\title{
Diversity and distribution of thermophilic hydrogenogenic carboxydotrophs revealed by microbial community analysis in sediments from multiple hydrothermal environments in Japan
}

\author{
Kimiho Omae $^{1} \cdot$ Yuto Fukuyama $^{1} \cdot$ Hisato Yasuda $^{2} \cdot$ Kenta Mise $^{1} \cdot$ Takashi Yoshida $^{1} \cdot$ Yoshihiko Sako $^{1}$ (D)
}

Received: 11 September 2018 / Revised: 15 March 2019 / Accepted: 15 April 2019 / Published online: 27 April 2019

(c) The Author(s) 2019

\begin{abstract}
In hydrothermal environments, carbon monoxide (CO) utilisation by thermophilic hydrogenogenic carboxydotrophs may play an important role in microbial ecology by reducing toxic levels of $\mathrm{CO}$ and providing $\mathrm{H}_{2}$ for fuelling microbial communities. We evaluated thermophilic hydrogenogenic carboxydotrophs by microbial community analysis. First, we analysed the correlation between carbon monoxide dehydrogenase (CODH)-energy-converting hydrogenase $(\mathrm{ECH})$ gene cluster and taxonomic affiliation by surveying an increasing genomic database. We identified 71 genome-encoded CODH-ECH gene clusters, including 46 whose owners were not reported as hydrogenogenic carboxydotrophs. We identified 13 phylotypes showing $>98.7 \%$ identity with these taxa as potential hydrogenogenic carboxydotrophs in hot springs. Of these, Firmicutes phylotypes such as Parageobacillus, Carboxydocella, Caldanaerobacter, and Carboxydothermus were found in different environmental conditions and distinct microbial communities. The relative abundance of the potential thermophilic hydrogenogenic carboxydotrophs was low. Most of them did not show any symbiotic networks with other microbes, implying that their metabolic activities might be low.
\end{abstract}

Keywords Microbial community analysis · Next-generation sequencing $\cdot$ Hot spring $\cdot$ Thermophile $\cdot$ Carboxydotroph . Hydrogenogen

\section{Introduction}

Hydrothermal systems, where geothermally heated water is expelled through fissures in the Earth's crust, are located both on land and under the sea. It is now well known that a wide variety of microorganisms, called thermophiles or hyperthermophiles, can prevail and even thrive in such

Communicated by Erko Stackebrandt.

Electronic supplementary material The online version of this article (https://doi.org/10.1007/s00203-019-01661-9) contains supplementary material, which is available to authorized users.

Yoshihiko Sako

sako@kais.kyoto-u.ac.jp

1 Laboratory of Marine Microbiology, Graduate School of Agriculture, Kyoto University, Kitashirakawa Oiwake-cho, Sakyo-ku, Kyoto 606-8503, Japan

2 Center for Advanced Marine Core Research, Kochi University, B200 Monobe, Nankoku, Kochi 783-8502, Japan high-temperature environments. The pioneering studies by Brock and his colleagues (Brock 1967; Bott and Brock 1969; Brock and Darland 1970; Brock et al. 1971) at the Yellowstone National Park hot springs established that these organisms grow at near boiling temperatures. Furthermore, a research study led by Pace using molecular phylogenetic techniques demonstrated the high abundance of unidentified thermophilic bacteria and archaea and their remarkable phylogenetic diversity in pink filaments and sediments in the same area (Barns et al. 1994, 1996; Reysenbach et al. 1994; Hugenholtz et al. 1998).

In recent years, microbes that can utilise carbon monoxide (CO) have been found from the hydrothermal area (Sokolova et al. 2009; Techtmann et al. 2009). Although CO is a toxic gas, it can also be a low-potential electron donor and carbon source for many microbes. To date, the list of known thermophilic anaerobic CO-utilizing microorganisms includes acetogenic bacteria (Moorella thermoacetica, for instance), sulfate-reducing bacteria (Desulfotomaculum carboxydivorans), methanogenic archaea (Methanothermobacter thermautotrophicus), and hydrogenogenic bacteria as 
well as various archaea, such as Carboxydothermus hydrogenoformans, Thermosinus carboxydivorans, and Thermococcus AM4 (Techtmann et al. 2009). Of these, hydrogenogenic bacteria and archaea (collectively designated thermophilic hydrogenogenic carboxydotrophs) are thought to play a key ecological role by virtue of providing a 'safety valve' for reducing toxic levels of $\mathrm{CO}$ and supplying $\mathrm{H}_{2}$ for fuelling $\mathrm{H}_{2}$-dependent microbial community processes (Techtmann et al. 2009).

In general, the ability of hydrogenogenic carboxydotrophy is linked to the presence of $\mathrm{CO}$ dehydrogenase $(\mathrm{CODH})$-energy-converting hydrogenase $(\mathrm{ECH})$ gene cluster in genomes. This cluster is believed to be horizontally transferred between the representatives of separate taxa (Techtmann et al. 2012). So far, 28 phylogenetically diverse thermophilic anaerobic hydrogenogenic CO-utilizing archaea and bacteria have been reported (Sokolova et al. 2009; Table 2). Most of them (23 species) are members of the phylum Firmicutes.

In addition to their basic isolation and identification, there are several ecological studies on thermophilic hydrogenogenic carboxydotrophs (Kochetkova et al. 2011; Brady et al. 2015; Yoneda et al. 2015). Notably, a radio isotopic study suggests that the majority of $\mathrm{CO}$ is oxidised to $\mathrm{CO}_{2}$ $\left(120 \mu \mathrm{mol} \mathrm{L} \mathrm{L}^{-1}\right.$ of sediment day $\left.{ }^{-1}\right)$ by microbial activities in the hot springs of Uzon Caldera (Kamchatka) (Kochetkova et al. 2011). Thermophilic hydrogenogenic carboxydotrophs of the genera Carboxydocella and Dictyoglomus have also been isolated from the same environment (Kochetkova et al. 2011). A quantitative polymerase chain reaction (qPCR) analysis targeting the CODH gene, which encodes a key enzyme involved in $\mathrm{CO}$ oxidation, suggests that the Carboxydothermus species, which is the most studied thermophilic carboxydotrophic species, is widely distributed in a wide range of hydrothermal environments despite its relatively low population size $(\leq 0.000795 \%$ of the total bacterial population) (Yoneda et al. 2015). In addition, using the stable isotope probing (SIP) method by ${ }^{13} \mathrm{CO}$ DNA, Thermincola, Desulfotomaculum, and Carboxydocella species were all detected and enriched at geothermal sites, although they are present at $<1 \%$ in the original communities (Brady et al. 2015). While there is evidence for the temporal dominance of the Carboxydothermus species ( $~ 10 \%$ of bacterial population) in hydrothermal environments (Yoneda et al. 2013a), thermophilic hydrogenogenic carboxydotrophs are generally considered to occur in low abundance in the environments.

However, these ecological studies on thermophilic hydrogenogenic carboxydotrophs had a few limitations. Because the sequences of CODH genes are highly diverse, it was difficult to design universal primers that could amplify a wide range of CODH genes from different taxa (Yoneda et al. 2013a). SIP is effective for identifying CO-utilizing microbes in the environment (Brady et al. 2015); however, cultivation bias could be observed. In addition, the previous CO-SIP study was limited to a few neutral $\mathrm{pH}$ hot springs (Brady et al. 2015). On the other hand, 16S metagenomics is a culture-independent and high-throughput technique, which is applicable for exploring diverse thermophilic hydrogenogenic carboxydotrophs and co-occurring microbes. The number of available microbial genome sequences has vastly increased thanks to recent advances in next-generation sequencing technology, using which CODH genes were detected in some species that had never been reported to show hydrogenogenic carboxydotrophic growth (Mohr et al. 2018; Inoue et al. 2019a). However, the correlation between the presence of CODH-ECH gene cluster and taxonomic affiliation has not been well understood. Here, we performed a comprehensive survey of a current prokaryotic genomic database and revealed the phylogenetic distribution of CODH-ECH gene clusters across prokaryotes. Next, we performed 16S rRNA gene amplicon (V3/V4 region) sequencing analysis on 100 sediment samples from a wide variety of hydrothermal and mesophilic environments in Japan and unveiled the distribution patterns of these "potential hydrogenogenic carboxydotrophs".

\section{Materials and methods}

\section{Sample collection and DNA extraction}

We collected a total of 100 sediment samples [17.5 99.0 ${ }^{\circ} \mathrm{C}$; $\mathrm{pH} 2.2 \sim 8.9$; oxidation-reduction potential (ORP) - 262 + $449 \mathrm{mV}$ ] from terrestrial hydrothermal and mesophilic environments in Japan from May 2014 to March 2017 (Online Resource 1). The sampling sites included 76 on Southern Kyushu Island (Kagoshima prefecture), 14 on Northern Kyushu Island (Oita prefecture), five on the Eastern Izu peninsula (Shizuoka prefecture), and five on the Southern Izu peninsula (Shizuoka prefecture). At the Unagionsen hot spring (Southern Kyushu Island), we collected a total of 65 samples in May 2014, May 2015, November 2015, and December 2016 as a previous study suggested that Carboxydothermus species are abundant in this environment (Yoneda et al. 2013a). In addition, we previously isolated the Carboxydocella strains ULO1 and JDF658 at Unagi-ike lake and the Jiunji-onsen hot spring, respectively (Fukuyama et al. 2017). Temperature was measured using a TX10 digital thermometer (Yokogawa, Tokyo, Japan) with a type K temperature probe (Yokogawa, Tokyo, Japan) at each sampling site. The $\mathrm{pH}$ and ORP of the sediment pore water were measured using an HM-31P portable $\mathrm{pH}$ meter (DKKTOA, Tokyo, Japan) with pH (GST-2729C; DKK-TOA, Tokyo, Japan) or ORP (PST-2729C; DKK-TOA, Tokyo, Japan) electrodes. Sediment samples were collected using 
$50 \mathrm{~mL}$ plastic tubes filled with pore water, put into plastic bags with AnaeroPouch-Anaero (Mitsubishi Gas Chemical, Tokyo, Japan), and immediately sealed to minimise contact with oxygen. The samples were then packed in a cooler box with ice, transported to the laboratory, and stored at $-80^{\circ} \mathrm{C}$ until use. DNA was extracted from $0.5 \mathrm{~g}$ of sediment material using an Extrap Soil DNA Kit Plus ver. 2 (Nippon Steel and SUMIKIN Eco-Tech, Tokyo, Japan) following the manufacturer's instructions. During the homogenising step, we used a bead beater-type homogeniser, Beads Crusher $\mu \mathrm{T}-12$ (Taitec, Koshigaya, Japan), at a speed of $3200 \mathrm{r} \mathrm{min}^{-1}$ for $60 \mathrm{~s}$. The extracted DNA was stored at $-30{ }^{\circ} \mathrm{C}$ until use.

\section{$16 S$ rRNA gene amplification and sequencing}

The V3/V4 region of bacterial and archaeal 16S rRNA genes was amplified with the following prokaryotic universal primer sets (Takahashi et al. 2014): forward (5'-CCTACG GGNBGCASCAG-3') and reverse (5'-GACTACNVGGG TATCTAATCC- $3^{\prime}$ ) with added overhanging adapter sequences at each 5 '-end according to the $16 \mathrm{~S}$ metagenomic sample preparation guide (https://support.illumina. com/content/dam/illumina-support/documents/documentat ion/chemistry_documentation/16s/16s-metagenomic-libra ry-prep-guide-15044223-b.pdf). Each sample was amplified with KAPA ${ }^{\mathrm{TM}} \mathrm{HiFi}$ HotStart ReadyMix (2X) (KAPA Biosystems, South Africa) according to the manufacturer's instructions. Paired-end (PE, $2 \times 300$ nucleotides) sequencing was performed with an Illumina MiSeq (MiSeq Reagent kit v2) and followed the manufacturer's run protocols (Illumina, Inc., San Diego, CA, USA).

\section{5 rRNA gene sequence processing and statistical analyses}

Primer-binding regions were removed by trimming 17 and $21 \mathrm{nt}$ sequences from the $5^{\prime}$ ends of the forward and reverse reads without adapter regions, respectively, with VSEARCH ver. 2.6.0 (Rognes et al. 2016). The reads were further processed by trimming low-quality regions from the sequences with Trimmomatic ver. 0.36 (SLIDINGWINDOW: 50:20) (Bolger et al. 2014). Using VSEARCH, the paired-end reads were joined and de-multiplexed, and a further round of quality control was conducted to remove sequences shorter than $200 \mathrm{nt}$ as well as those containing ambiguous bases $(N)$ or bases with a quality score below 20. Chimeric 16S rDNA sequences were detected using the UCHIME algorithm in the USEARCH package implemented within VSEARCH. The SILVA 132 SSU Ref Nr99 (Quast et al. 2013), a comprehensive, quality checked data sets of small subunit rRNA sequences, was used as a reference for chimera detection. Operational taxonomic units (OTUs) were defined as clusters of sequences that were not singletons (unique sequences that are present exactly once in each sample) with $98.7 \%$ similarity using VSEARCH. Then, taxonomic classification of individual OTU was performed with the stand-alone SINA ver. 1.2.11 aligner (Pruesse et al. 2012) using the SILVA 132 SSU Ref Nr99 database as a reference. The non-prokaryotic OTUs (i.e., eukaryote and unclassified domain) were then removed. OTU abundance was estimated by adding prokaryotic singleton reads using the global alignment search option of VSEARCH (-usearch_global-id 0.987), to increase sensitivity. Prior to community analysis, samples with less than 10,000 sequences were omitted (leaving 77 samples) in the beta-diversity patterns. The resulting OTU abundance tables were rarefied to an even number of sequences per sample to ensure equal sampling depth $(14,146$ sequences per sample) using the vegan package (Oksanen et al. 2017) of the R software (R Core Team 2016). Alpha and beta diversity analyses were then performed with the phyloseq (McMurdie and Holmes 2013) and vegan packages of the R software.

\section{Database search for CODH-ECH gene clusters}

The amino acid sequences corresponding to CODHs were obtained from the Reference Sequence (RefSeq) Database in National Center for Biotechnology Information (NCBI) (December 2018) through a BLASTp search using $C$. hydrogenoformans CooSI (ABB14432.1) subunit as a query. Low-scoring and short-length hits (bit score $<200$, amino acid length $<550$ ) including HCPs and partial fragments were excluded from the data set. Then, coding sequences (CDS) within 20 CDSs upstream and downstream of the $\mathrm{CODH}$ gene locus were annotated by clusters of orthologous groups of proteins (COGs) (Tatusov 2001) through RPS-BLAST search $\left(e\right.$ value $\left.<10^{-6}\right)$ using NCBI Conserved Domain Database (Marchler-Bauer et al. 2002). Of these, we identified CODH genes with ECH small and large subunits (COG3260 nd COG3261, respectively) as CODH-ECH gene clusters.

\section{Phylogenetic analyses}

We retrieved the reference $16 \mathrm{~S}$ rRNA gene sequences that were equal or longer than $1,000 \mathrm{nt}$ and did not include $N$ from the genomes of prokaryotes possessing $\mathrm{CODH}-\mathrm{ECH}$ gene clusters and those that were classified into the same genera as them via the RefSeq genome database. To obtain a non-redundant data set for phylogenetic analysis, retrieved sequences were trimmed into V3/V4 region identical to 
the amplicons and clustered with $100 \%$ similarity using VSEARCH (the sequences utilised in this analysis are listed in Online Resource 6). The sequences were aligned using MAFFT 7.402 (Katoh and Standley 2013). Maximum-likelihood phylogenetic trees were calculated using FastTree ver. 2.1.9 (Price et al. 2010) with an approximate-maximum-likelihood method using the GTR + GAMMA model. Robustness of the topology of the phylogenetic trees was evaluated by local bootstrap values based on 1000 re-samples. The tree was imported into the iTOL online tool (Letunic and Bork 2016) for visualisation.

\section{Exploring the co-occurrence of thermophilic hydrogenogenic carboxydotrophs and other microbes}

Based on the OTU read numbers, a network of phylotype co-occurrence was produced with a minimum Spearman correlation coefficient of 0.8 using R. We retrieved and have presented the smaller networks, including phylotypes, related to the thermophilic hydrogenogenic carboxydotrophs identified in our phylogenetic analysis.

\section{Results and discussion}

\section{Sample profiles and overview of 16S rRNA gene amplicon sequencing}

We collected 100 sediment samples from geographically distant areas in Japan, including Kyushu Island and the Izu Peninsula (Table 1; additional data are provided in Online Resource 1). Except for a single sample from Unagi-ike lake, which has a moderate environment $\left(17.5^{\circ} \mathrm{C} ; \mathrm{pH} 7.37\right.$; ORP, $+75 \mathrm{mV}$ ), all the samples were collected from geothermally heated hydrothermal environments $\left(33.8-99.0^{\circ} \mathrm{C}\right)$.
Although the in situ environmental conditions of the sampling sites were variable, the hot springs on Kyushu Island had an acidic $\mathrm{pH}$ [average $\mathrm{pH} 4.1 \pm 1.1$ (sd); measurable sites, $n=82$ ], whereas those on the Izu Peninsula were neutral or weakly alkaline (pH $8.3 \pm 0.4 ; n=10)$.

Our 16S rRNA gene amplicon sequencing analysis generated 8,531,132 bacterial and archaeal quality-controlled sequences from the 100 samples, with a range of 107-398,919 sequences (average, 85,311 sequences) per sample (Online Resource 1). A total of 9,394 prokaryotic OTUs were defined at the $98.7 \%$ similarity level, and 23-4,737 OTUs (average, 299 OTUs) were observed in each sample (Online Resource 2). Diversity analysis using rarefied 77 samples with equal or greater than 10,000 sequences revealed that microbial communities in the sampled hot springs showed much lower alpha diversity than those in the moderate environment (Unagi-ike lake; Online Resource 3 ), indicating that high temperature imposed constraints on community properties as observed in other studies (Sharp et al. 2014).

Furthermore, our beta diversity analysis revealed apparent differences between the acidic hot springs on Kyushu Island and the neutral or weak alkaline environments on Izu Peninsula and Unagi-ike lake (Fig. 1). At the domain level, microbial communities in the acidic hot springs were dominated by archaea, whereas those in the neutral or weak alkaline environments were dominated by bacteria (Online Resource 4). The phylotypes that shared $100 \%$ identity with Vulcanisaeta souniana (phylum Crenarchaeota; OTU_1) and Thermus thermophilus (phylum Deinococcus-Thermus; OTU_20) were notably prominent in the acidic hot springs and neutral or weak alkaline environments, respectively. $V$. souniana is a heterotrophic anaerobic hyperthermophilic crenarchaeote found in hot springs that grows optimally at 85-90 ${ }^{\circ} \mathrm{C}$ and $\mathrm{pH} 4.0-4.5$ (Itoh et al. 2002). In contrast, T.thermophilus is an extremely thermophilic bacterium also found in hot springs, but its optimal growth occurs at

Table 1 Summary of samples

\begin{tabular}{lllllcc}
\hline Sampling area and time point & Sampling date & $\begin{array}{l}\text { Numbers of } \\
\text { samples }\end{array}$ & Temperature $\left({ }^{\circ} \mathrm{C}\right)$ & pH & ORP $(\mathrm{mV})$ & Salinity $(\%)$ \\
\hline 1405_Unagi & May 2014 & 13 & $41.4 \sim 99.0$ & $2.2 \sim 4.9$ & $-218 \sim+426$ & n.m \\
1505_Unagi & May 2015 & 15 & $33.8 \sim 95.8$ & $4.4 \sim 5.8$ & $-174 \sim+277$ & n.m \\
1511_Unagi & November 2015 & 19 & $41.2 \sim 96.2$ & $3.3 \sim 5.6$ & $-130 \sim+449$ & n.m \\
1612_Unagi & December 2016 & 18 & $35.5 \sim 96.9$ & $2.6 \sim 5.9$ & $-262 \sim+164$ & n.m \\
1612_Kirishima & December 2016 & 10 & $63.4 \sim 88.7$ & $2.4 \sim 4.1$ & $-179 \sim+310$ & 0 \\
1703_Komatsu & March 2017 & 14 & $61.1 \sim 80.9$ & $2.2 \sim 5.6$ & $-179 \sim+286$ & n.m \\
1501_Eastern_Izu & January 2015 & 5 & $68.2 \sim 80.1$ & $8.4 \sim 8.5$ & $-22 \sim+189$ & $0.0 \sim 0.2$ \\
1501_Southern_Izu & January 2015 & 5 & $60.1 \sim 78.5$ & $7.7 \sim 8.9$ & $-30 \sim+259$ & $0.0 \sim 2.4$ \\
1612_Unagi-ike_lake & December 2016 & 1 & 17.5 & 7.37 & 75 & n.m \\
\hline
\end{tabular}

n.m. not measured 

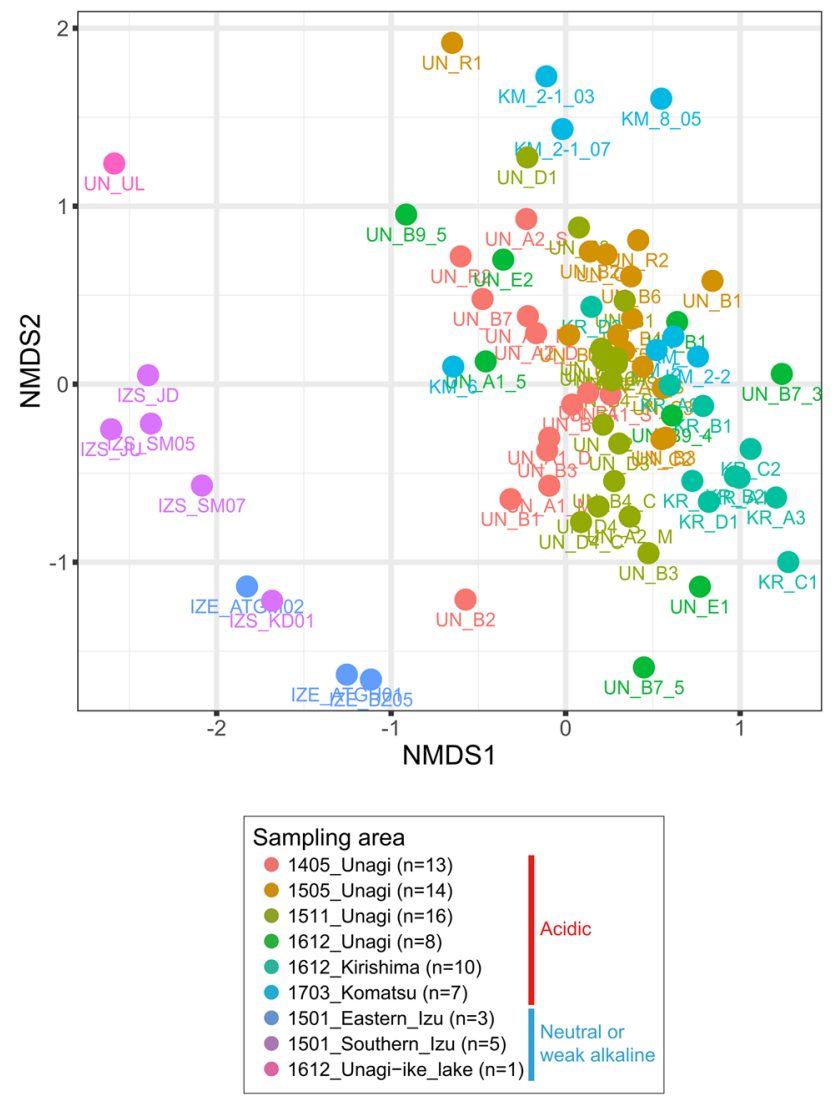

Fig. 1 Non-metric multidimensional scaling analysis based on BrayCurtis dissimilarity. Plot colours illustrate sampling area and period

65-72 ${ }^{\circ} \mathrm{C}$ and $\mathrm{pH} 7.5$ (Oshima and Imahori 1974). Although the major phylotypes were the same in each acidic and neutral or weak alkaline environments, our non-metric multidimensional scaling analysis using rarefied 77 samples with greater equal than 10,000 sequences shows that microbial community compositions vary across each sampling sites (Fig. 1).

\section{CODH-ECH gene clusters found in prokaryotic genomes}

A previous study examined CODHs and their genomic context in 2887 microbial genomes and revealed 185 genomes that encoded at least one CODH gene (Techtmann et al. 2012). Of these, 12 genomes possessed CODH-ECH gene clusters. However, by December 2018, the number of sequenced microbial genome entries in the RefSeq genome database had reached 142,909, and novel thermophilic hydrogenogenic carboxydotrophs had been reported. Therefore, we searched CODH-ECH gene clusters in the current RefSeq database and examined their taxonomic information. We identified 71 genomes encoding CODH-ECH gene clusters, which include 40 thermophile genomes (14 genera), 25 mesophile genomes (12 genera), and six unclassified microbial genomes (Table 2; additional data are listed in Online Resource 5). All mesophilic members were classified into the phylum Proteobacteria, which included phototrophic bacteria or sulfate-reducing bacteria, whereas thermophilic members were phylogenetically diverse and classified into the phylum Crenarchaeota, Euryarchaeota, and Firmicutes. Of these 71 genomes, 46 have never been reported as hydrogenogenic carboxydotrophs (Table 2), and the presence of CODH-ECH gene clusters in 22 genomes was reported for the first time in this study (Online Resource 5).

Conservation patterns of CODH-ECH gene clusters were different in each genus (Fig. 2). We classified these genera into three groups: (1) the CODH-ECH gene clusters and the hydrogenogenic carboxydotrophy ability were well conserved; (2) a portion of members conserved the CODH-ECH gene clusters; and (3) genera that we could not classify into (1) nor (2) because of inadequate availability of genomic information. Thermincola, Carboxydocella, Carboxydothermus, and Caldanaerobacter were classified into the group (1). In most cases, the phylogeny of CODH genes was corresponding to their taxonomic phylogeny in this group (Adam et al. 2018; Fukuyama et al. 2018; Toshchakov et al. 2018), suggesting that the CODH-ECH gene clusters descended from the common ancestors of each genus. The genus Carboxydothermus has been one of the most studied models of thermophilic carboxydotrophy, and the members of this genus possess four or five CODH genes (Fukuyama et al. 2018). A comparative genomic analysis in Carboxydothermus revealed that the $\mathrm{CODH}-\mathrm{ECH}$ gene clusters were conserved in the members except for $C$. pertinax, which lacked only the $\mathrm{CODH}$ (CODHI) unit of CODH-ECH gene cluster and Carboxydothermus ferrireducens, which lacked the whole CODH-ECH gene cluster (Fukuyama et al. 2018). C. ferrireducens can grow carboxydotrophically, but is not hydrogenogenic (Slobodkin et al. 2006). On the other hand, C.pertinax can grow by hydrogenogenic carboxydotrophy (Yoneda et al. 2012), and it is suggested that $C$. pertinax could couple alternative CODH (CODH-II) to the distal ECH (Fukuyama et al. 2018). $C$. pertinax was the only isolate that could grow by hydrogenogenic carboxydotrophy without the CODH-ECH gene cluster. Caldanaerobacter subterraneus subspecies can oxidise $\mathrm{CO}$ and possess CODH-ECH gene clusters, whose structures are very similar (Sant'Anna et al. 2015). However, phylogenetic reconstruction of $\mathrm{CODH}$ genes revealed that $\mathrm{CODH}$ genes from C. subterraneus have distinct evolutionary histories. It is suggested that replacement of CODH gene occurred by a horizontal gene transfer event in C. subterraneus subsp. tengcongensis and C. subterraneus subsp. yonseiensis (Sant'Anna et al. 2015). Thermococcus, Thermofilum, Thermoanaerobacter, Moorella, Desulfotomaculum, Desulfosporosinus, Parageobacillus, and members of the phylum Proteobacteria were 
Table 2 Prokaryotes possessing CODH-ECH gene clusters

\begin{tabular}{|c|c|c|c|}
\hline \multirow[t]{2}{*}{ Organism } & \multirow{2}{*}{$\begin{array}{l}\text { Hydrogenogenic carboxydotrophic } \\
\text { growth }\end{array}$} & \multicolumn{2}{|l|}{ Isolation source } \\
\hline & & Type & References \\
\hline \multicolumn{4}{|l|}{ Crenarchaeota (thermophilic) } \\
\hline $\begin{array}{l}\text { Thermofilum carboxyditrophus } \\
1505\end{array}$ & Yes (Sokolova et al. 2009) & Water and mud & Sokolova et al. (2009) \\
\hline \multicolumn{4}{|l|}{ Euryarchaeota (thermophilic) } \\
\hline Thermococcus barophilus CH5 & Yes (Kozhevnikova et al. 2016) & Deep-sea hydrothermal fields & Kozhevnikova et al. (2016) \\
\hline Thermococcus barophilus MP & Yes (Kozhevnikova et al. 2016) & Deep-sea hydrothermal fields & Kozhevnikova et al. (2016) \\
\hline $\begin{array}{l}\text { Thermococcus guaymasensis DSM } \\
11113\end{array}$ & n.r & Hydrothermal vent sediment & Canganella et al. (1998) \\
\hline Thermococcus onnurineus NA1 & Yes (Bae et al. 2006) & Deep-sea hydrothermal fields & Bae et al. (2006) \\
\hline Thermococcus paralvinellae $\mathrm{ES} 1$ & n.r & Active hydrothermal vent chimneys & Hensley et al. (2014) \\
\hline Thermococcus sp. AM4 & Yes (Sokolova et al. 2004b) & Active chimney & Sokolova et al. (2004b) \\
\hline \multicolumn{4}{|l|}{ Firmicutes (thermophilic) } \\
\hline $\begin{array}{l}\text { Parageobacillus thermoglucosida- } \\
\text { sius } \mathrm{B} 4168\end{array}$ & n.r & n.r & n.r \\
\hline $\begin{array}{l}\text { Parageobacillus thermoglucosida- } \\
\text { sius C56-YS93 }\end{array}$ & n.r & n.r & n.r \\
\hline $\begin{array}{l}\text { Parageobacillus thermoglucosida- } \\
\text { sius DSM } 2542^{\mathrm{a}}\end{array}$ & Yes (Mohr et al. 2018) & n.r & Suzuki et al. (1983) \\
\hline $\begin{array}{l}\text { Parageobacillus thermoglucosida- } \\
\text { sius GT23 }\end{array}$ & n.r & n.r & n.r \\
\hline $\begin{array}{l}\text { Parageobacillus thermoglucosida- } \\
\text { sius NBRC } 107763\end{array}$ & n.r & n.r & n.r \\
\hline $\begin{array}{l}\text { Parageobacillus thermoglucosida- } \\
\text { sius NCIMB } 11955\end{array}$ & n.r & n.r & n.r \\
\hline $\begin{array}{l}\text { Parageobacillus thermoglucosida- } \\
\text { sius TG4 }\end{array}$ & Yes (Inoue et al. 2019b) & Marine sediment & Inoue et al. (2019a) \\
\hline $\begin{array}{l}\text { Parageobacillus thermoglucosida- } \\
\text { sius TM242 }\end{array}$ & n.r & n.r & n.r \\
\hline $\begin{array}{l}\text { Parageobacillus thermoglucosida- } \\
\text { sius TNO-09.020 }\end{array}$ & n.r & n.r & n.r \\
\hline $\begin{array}{l}\text { Parageobacillus thermoglucosida- } \\
\text { sius } \text { Y4.1MC1 }\end{array}$ & n.r & n.r & n.r \\
\hline Carboxydocella sp. JDF658 & Yes (Fukuyama et al. 2017) & $\begin{array}{l}\text { Open-air stream from a hot spring } \\
\text { well }\end{array}$ & Fukuyama et al. (2017) \\
\hline Carboxydocella sp. ULO1 & Yes (Fukuyama et al. 2017) & Sediment of a maar lake & Fukuyama et al. (2017) \\
\hline $\begin{array}{l}\text { Carboxydocella sporoproducens } \\
\text { DSM } 16521\end{array}$ & Yes (Slepova et al. 2006) & Hot spring & Slepova et al. (2006) \\
\hline $\begin{array}{l}\text { Carboxydocella thermautotrophica } \\
019\end{array}$ & Yes (Toshchakov et al. 2018) & Thermal field & Toshchakov et al. (2018) \\
\hline $\begin{array}{l}\text { Carboxydocella thermautotrophica } \\
041\end{array}$ & Yes (Sokolova et al. 2002) & Terrestrial hot vent & Sokolova et al. (2002) \\
\hline Desulfosporosinus sp. OL & n.r & n.r & n.r \\
\hline $\begin{array}{l}\text { Desulfotomaculum nigrificans CO- } \\
\text { 1-SRB }\end{array}$ & Yes (Parshina et al. 2005) & Anaerobic bioreactor sludge & Sokolova et al. (2009) \\
\hline Thermincola ferriacetica Z-0001 & Yes (Zavarzina et al. 2007) & $\begin{array}{l}\text { Ferric deposits of a terrestrial } \\
\text { hydrothermal spring }\end{array}$ & Zavarzina et al. (2007) \\
\hline Thermincola potens JR & $\begin{array}{l}\text { Yes (Wrighton et al. 2008; Byrne- } \\
\text { Bailey et al. 2010) }\end{array}$ & Thermophilic microbial fuel cell & $\begin{array}{l}\text { Wrighton et al. (2008); Byrne- } \\
\text { Bailey et al. (2010) }\end{array}$ \\
\hline $\begin{array}{l}\text { Caldanaerobacter subterraneus } \\
\text { subsp. pacificus DSM } 12653\end{array}$ & $\begin{array}{l}\text { Yes (Sokolova et al. 2001; Fardeau } \\
\text { et al. 2004) }\end{array}$ & Oilfields & Fardeau et al. (2004) \\
\hline $\begin{array}{l}\text { Caldanaerobacter subterraneus } \\
\text { subsp. tengcongensis MB4 }\end{array}$ & n.r & Oilfields & Fardeau et al. (2004) \\
\hline
\end{tabular}


Table 2 (continued)

\begin{tabular}{|c|c|c|c|}
\hline \multirow[t]{2}{*}{ Organism } & \multirow{2}{*}{$\begin{array}{l}\text { Hydrogenogenic carboxydotrophic } \\
\text { growth }\end{array}$} & \multicolumn{2}{|l|}{ Isolation source } \\
\hline & & Type & References \\
\hline $\begin{array}{l}\text { Caldanaerobacter subterraneus } \\
\text { subsp. yonseiensis } \mathrm{KB}-1\end{array}$ & n.r & Oilfields & Fardeau et al. (2004) \\
\hline Calderihabitans maritimus $\mathrm{KKC1}$ & Yes (Yoneda et al. 2013b) & Submerged marine caldera & Yoneda et al. (2013b) \\
\hline $\begin{array}{l}\text { Carboxydothermus hydrogenofor- } \\
\text { mans Z-2901 }\end{array}$ & Yes (Svetlichny et al. 1991) & Hot swamp & Svetlichny et al. (1991) \\
\hline Carboxydothermus islandicus SET & Yes (Novikov et al. 2011) & Hot spring & Novikov et al. (2011) \\
\hline Moorella glycerini NMP & n.r & Underground gas storage & Slobodkin et al. (1997) \\
\hline Moorella sp. Hama-1 & n.r & $\begin{array}{l}\text { Thermophilic anaerobic digestion } \\
\text { reactor }\end{array}$ & Harada et al. (2018) \\
\hline Moorella stamsii DSM 26271 & Yes (Alves et al. 2013) & Anaerobic sludge & Alves et al. (2013) \\
\hline $\begin{array}{l}\text { Moorella thermoacetica DSM } \\
21394\end{array}$ & Yes (Jiang et al. 2009) & Anaerobic bioreactors & Jiang et al. (2009) \\
\hline $\begin{array}{l}\text { Thermanaeromonas toyohensis } \\
\text { ToBE }\end{array}$ & n.r & Geothermal aquifer in mine & Mori et al. (2002) \\
\hline Thermoanaerobacter sp. YS13 & n.r & Geothermal hot spring & Peng et al. (2016) \\
\hline Thermosinus carboxydivorans Nor1 & Yes (Sokolova et al. 2004a) & Hot spring & Sokolova et al. (2004a) \\
\hline \multicolumn{4}{|l|}{ Proteobacteria (mesophilic) } \\
\hline $\begin{array}{l}\text { Rhodopseudomonas palustris } \\
\text { BisB18 }\end{array}$ & n.r & River sediment & Oda et al. (2008) \\
\hline $\begin{array}{l}\text { Pleomorphomonas carboxyditropha } \\
\text { SVCO-16 }\end{array}$ & n.r & Anaerobic sludge & Esquivel-Elizondo et al. (2018) \\
\hline Pseudovibrio sp. POLY-S9 & n.r & Intertidal marine sponge & Alex and Antunes (2015) \\
\hline Pseudovibrio sp. Tun.PSC04-5.I4 & n.r & n.r & n.r \\
\hline $\begin{array}{l}\text { Rhodospirillum rubrum ATCC } \\
11170\end{array}$ & Yes (Kerby et al. 1992) & Fresh water & Munk et al. (2011) \\
\hline Rhodospirillum rubrum F11 & Yes (Singer et al. 2006) & n.r & n.r \\
\hline $\begin{array}{l}\text { Desulfovibrio bizertensis DSM } \\
18034\end{array}$ & n.r & Marine sediment & Haouari et al. (2006) \\
\hline $\begin{array}{l}\text { Pseudodesulfovibrio piezophilus } \\
\text { C1TLV30 }\end{array}$ & n.r & Wood falls at deep sea & Khelaifia et al. (2011) \\
\hline Geobacter bemidjiensis Bem & n.r & Subsurface sediments & Nevin et al. (2005) \\
\hline Geobacter pickeringii G13 & n.r & Kaolin clays & Shelobolina et al. (2007) \\
\hline Ferrimonas futtsuensis DSM 18154 & n.r & Sediment & Nakagawa et al. (2006) \\
\hline $\begin{array}{l}\text { Ferrimonas kyonanensis DSM } \\
18153\end{array}$ & n.r & Alimentary tract of littleneck clams & Nakagawa et al. (2006) \\
\hline Ferrimonas sediminum DSM 23317 & n.r & Coastal sediment & Ji et al. (2013) \\
\hline Shewanella sp. M2 & n.r & n.r & n.r \\
\hline Shewanella sp. R106 & n.r & n.r & n.r \\
\hline Citrobacter amalonaticus Y19 & Yes (Oh et al. 2008) & $\begin{array}{l}\text { Anaerobic wastewater sludge } \\
\text { digester }\end{array}$ & Jung et al. (1999) \\
\hline $\begin{array}{l}\text { Salmonella enterica subsp. enterica } \\
\text { serovar Montevideo } 50262\end{array}$ & n.r & n.r & n.r \\
\hline $\begin{array}{l}\text { Salmonella enterica subsp. enterica } \\
\text { serovar Montevideo } 50270\end{array}$ & n.r & n.r & n.r \\
\hline $\begin{array}{l}\text { Salmonella enterica subsp. enterica } \\
\text { serovar Senftenberg } 50263\end{array}$ & n.r & n.r & n.r \\
\hline $\begin{array}{l}\text { Salmonella enterica subsp. enterica } \\
\text { serovar Senftenberg } 50264\end{array}$ & n.r & n.r & n.r \\
\hline $\begin{array}{l}\text { Salmonella enterica subsp. enterica } \\
\text { serovar Senftenberg } 50265\end{array}$ & n.r & n.r & n.r \\
\hline $\begin{array}{l}\text { Salmonella enterica subsp. enterica } \\
\text { serovar Senftenberg } 50271\end{array}$ & n.r & n.r & n.r \\
\hline
\end{tabular}


Table 2 (continued)

\begin{tabular}{|c|c|c|c|}
\hline \multirow[t]{2}{*}{ Organism } & \multirow{2}{*}{$\begin{array}{l}\text { Hydrogenogenic carboxydotrophic } \\
\text { growth }\end{array}$} & \multicolumn{2}{|l|}{ Isolation source } \\
\hline & & Type & References \\
\hline $\begin{array}{l}\text { Salmonella enterica subsp. enterica } \\
\text { serovar Senftenberg } 50272\end{array}$ & n.r & n.r & n.r \\
\hline $\begin{array}{l}\text { Salmonella enterica subsp. enterica } \\
\text { serovar Senftenberg SS209 }\end{array}$ & n.r & n.r & n.r \\
\hline Photobacterium marinum AK15 & n.r & Sediment & Srinivas et al. (2013) \\
\hline Uncultured & & n.r & n.r \\
\hline $\begin{array}{l}\text { Candidatus Korarchaeota archaeon } \\
\text { MDKW }\end{array}$ & n.r & Hot springs metagenomes & n.r \\
\hline Clostridiales bacterium DRI-13 & n.r & Subglacial ecosystem & n.r \\
\hline Rhizobiales bacterium AFS016371 & n.r & Soil & n.r \\
\hline Rhizobiales bacterium AFS041951 & n.r & Soil & n.r \\
\hline Rhizobiales bacterium AFS049984 & n.r & Soil & n.r \\
\hline Rhizobiales bacterium AFS089140 & n.r & Soil & n.r \\
\hline
\end{tabular}

n.r. not reported

${ }^{\mathrm{a}}$ Two genomes are available for this strain in the database

classified into group (2). Because most species of Thermococcus, Thermofilum, Thermoanaerobacter, Desulfotomaculum, and Desulfosporosinus did not possess the CODH-ECH gene clusters, it was suggested that $\mathrm{CODH}-\mathrm{ECH}$ gene clusters might have been obtained by a portion of the members in a horizontal gene transfer event. In fact, this cluster is believed to be horizontally transferred between the representatives of separate taxa (Techtmann et al. 2012). In the genus Moorella, Moorella stamsii and Moorella glycerini possessed identical CODHs that were flanked by ECH gene clusters. Moorella sp. Hama-1 and Moorella thermoacetica DSM 21394, which formed a different subclade from $M$. stamsii and M. glycerini, also possessed a similar CODH-ECH gene cluster. However, it was revealed that the other $11 \mathrm{M}$. thermoacetica strains did not possess the CODH-ECH gene cluster (Online Resource 5). M. thermoacetica might be an acetogenic carboxydotroph rather than being hydrogenogenic, as reported previously (Pierce et al. 2008; Schuchmann and Müller 2014), and only strain DSM 21394 might be hydrogenogenic. Parageobacillus thermoglucosidasius is the only facultative anaerobic bacillus among the thermophilic hydrogenogenic carboxydotrophic species (Mohr et al. 2018). Although other Parageobacillus species did not possess the CODH-ECH gene cluster, $P$. thermoglucosidasius possesses a $\mathrm{CODH}-\mathrm{ECH}$ gene cluster that is phylogenetically related to those of Moorella and Caldanaerobacter (Mohr et al. 2018). Unlike M. thermoacetica, all 10 genomes of $P$. thermoglucosidasius have conserved the $\mathrm{CODH}-\mathrm{ECH}$ gene clusters (Online Resource 5), and hydrogenogenic carboxydotrophy might be an important trait for this species. The other species, Thermanaeromonas toyohensis, Thermosinus carboxydivorans, Calderihabitans maritimus, and uncultured archaea and bacteria (Candidatus Korarchaeota archaeon MDKW, Clostridium bacterium DRI-13, and Rhizobiales bacterium) were classified into the group (3).

\section{Diversity and distribution of thermophilic hydrogenogenic carboxydotrophs}

In the $16 \mathrm{~S}$ amplicon sequencing analysis, we revealed that the representative sequences of 13 phylotypes showed $>98.7 \%$ identity with known thermophilic hydrogenogenic carboxydotrophs or microbes possessing CODH-ECH gene clusters, and 10 phylotypes were members of the phylum Firmicutes (Fig. 2, Online Resource 7). Of these, the representative sequences of OTU_1654 and OTU_3578 were identical to Carboxydocella species and C. pertinax, respectively, and OTU_664 and OTU_1148 showed $98.8 \%$ and $99.5 \%$ identities with $C$. subterraneus subspecies, respectively. They were members of group (1). It should be noted that the abundant phylotype OTU_1160 showed $97.7 \%$ identity with Carboxydothermus species, all of which possess multi CODH gene clusters. The phylotypes that were close to Thermofilum carboxyditrophus 1505 (OTU_1051, identity =99\%), M. thermoacetica DSM 21394 (OTU_1621, identity =98.8\%; OTU_6791, identity $=99.1 \%)$, M. glycerini DSM 26271 or $M$. stamsii NMP (OTU_1692, identity $=99.3 \%)$, Thermoanaerobacter $\mathrm{sp}$. YS13 (OTU_1749, identity =100\%), Thermococcus barophilus (OTU_1816, identity=99\%), T. toyohensis ToBE (OTU_6523, identity $=99.3 \%$ ), and $P$. thermoglucosida sius (OTU_8267, identity $=100 \%$ ), were members of group (2) hydrogenogenic carboxydotrophs, suggesting that these phylotypes are also potential thermophilic hydrogenogenic 


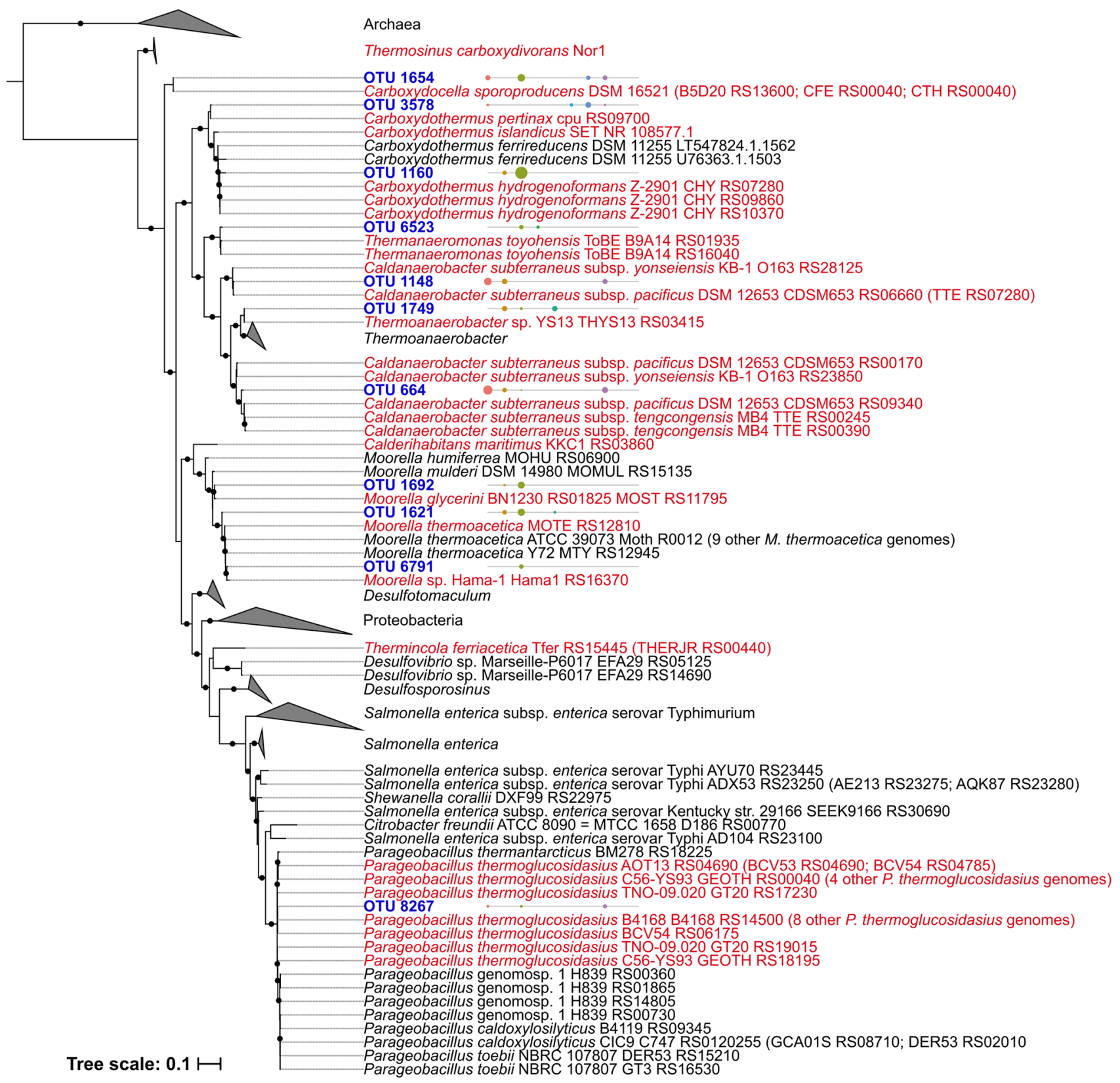

\begin{tabular}{|c|c|}
\hline $\begin{array}{l}\text { Abundance } \\
-1 \\
\cdot: 4 \\
-64 \\
-16384\end{array}$ & $\begin{array}{l}\text { 1405_Unagi } \\
\text { 1505_Unagi } \\
\text { 1511_Unagi } \\
\text { 1612_Unagi } \\
\text { 1612_Kirishima } \\
\text { 1703_Komatsu } \\
\text { 1501_Eastern_Izu } \\
\text { 1501_Southern_Izu } \\
\text { 1612_Unagi-ike_lake }\end{array}$ \\
\hline
\end{tabular}

Fig. 2 Phylogenetic reconstruction of potential thermophilic hydrogenogenic carboxydotrophic phylotypes of the Phylum Firmicutes. The 16S rRNA sequences used in this analysis are listed in Online Resource 6. Other but identical sequences to their leaves are shown in parenthesis (only one sequence per genome are shown). The phylotype sequences obtained in this study are expressed by 'operational taxonomic unit (OTU)' prefix. Microbes possessing $\mathrm{CODH}-\mathrm{ECH}$ gene clusters and Carboxydothermus pertinax (cpu_RS09700) are shown in red font. Nodes supported by a bootstrap value greater than $80 \%$ are indicated by black circles. The bubble plots which are shown at the right of OTUs display the distribution pattern of each phylotype. Abundance is indicated by the number of amplicon reads in each sample 
carboxydotrophs. We also found that OTU_1000 showed 99\% identity with Candidatus Korarchaeota archaeon MDKW, whose genome was assembled from Washburn Hot Spring metagenome.

The 13 phylotypes of potential thermophilic hydrogenogenic carboxydotrophs were detected in 45 samples (Fig. 2, Online Resource 7). Of these, OTU_1654 (Carboxydocella), OTU_664 (C. subterraneus), OTU_1148 (C. subterraneus), OTU_3578 (C. pertinax), and OTU_8267 (P. thermoglucosidasius) were detected in 7 to 21 samples and widely distributed in geographically distinct areas (both Kyushu Island and the Izu Peninsula) that showed different environmental conditions and microbial community structures (Fig. 2, Online Resource 7). OTU_1000, uncultured archaeon phylotype, was also detected widely from 11 samples. The distribution of OTU_1051 (T. carboxyditrophus), OTU_1692 (M. glycerini or M. stamsii), OTU_1749 (Thermoanaerobacter sp. YS13), OTU_6523 (T. toyohensis), OTU_1621 (M. thermoacetica DSM 21394), and OTU_6791 (M. thermoacetica DSM 21394) was limited to hot springs in Kyushu Island (mainly in Unagi-onsen in May 2015, November 2015, and December 2016). OTU_1816, the phylotype of T. barophilus that was isolated from a deep-sea hydrothermal vent (Marteinsson et al. 1999), was uniquely detected in the saline hot springs in the Izu Peninsula (Online Resource 7).

In most cases, the phylotypes of potential thermophilic hydrogenogenic carboxydotrophs showed a relative abundance of $<0.1 \%$. Previous studies also suggested that Firmicutes carboxydotroph abundance in hydrothermal environments is usually low (Brady et al. 2015; Yoneda et al. 2015). However, the phylotypes of C. subterraneus (OTU_664), Carboxydocella (OTU_1654), C. pertinax (OTU_3578), and Carboxydothermus phylotype (OTU_1160) exhibited a relative abundance of $>0.1 \%$ in nine samples (Online Resource 7). In particular, we found that the relative abundance of OTU_1654 reached $8.47 \%$ per sample at the 1511 UN A2_D site $\left(70.9{ }^{\circ} \mathrm{C}, \mathrm{pH} 4.68\right)$. OTU_1160 was abundant in Unagi-onsen in November 2015, and its relative abundance reached $7.75 \%$ and $11 \%$ at the 1511_UN_A2_D and 1511_UN_B4_C $\left(94.9{ }^{\circ} \mathrm{C}, \mathrm{pH} 3.65\right)$ sites, respectively. However, we could not identify whether the phylotypes, whose relative abundance exceeded $0.1 \%$ were growing in these environments, because six of the nine sites showed higher temperature or lower $\mathrm{pH}$ than the growth conditions for the isolates of $C$. subterraneus subspecies $\left(50-80{ }^{\circ} \mathrm{C}\right.$, pH 4.5-9.0) (Fardeau et al. 2004), Carboxydocella species $\left(40-70{ }^{\circ} \mathrm{C}\right.$, pH 6.2-8.0) (Sokolova et al. 2002; Slepova et al. 2006; Toshchakov et al. 2018), and Carboxydothermus species $\left(40-78{ }^{\circ} \mathrm{C}, \mathrm{pH} 4.6-8.6\right)$ (Svetlichny et al. 1991; Novikov et al. 2011; Yoneda et al. 2012) (Online Resource 8). The other three sites including 1511_UN_A2_D showed moderate environmental conditions, where the growth could occur (Online Resource 8), but the DNA yields from these sites were low ( $<15 \mathrm{ng} / \mathrm{g}$ sediment). Firmicutes members of Carboxydothermus, Carboxydocella, and Caldanaerobacter are reported to be able to form endospore (Kim et al. 2001; Wu et al. 2005; Slepova et al. 2006). Notably, these groups possessed the genes for endospore formation. It was speculated that DNAs of these phylotypes might persist in such environments longer than those of non-spore-forming prokaryotes.

Carboxydotrophs have been suggested to be functionally important, because they mediate a 'currency exchange' between $\mathrm{CO}$ and hydrogen in hydrothermal environments (Techtmann et al. 2009). For example, symbiotic interactions have been observed between $C$. hydrogenoformans and thermophilic sulfate reducers in culture, wherein the carboxydotroph provides protection from $\mathrm{CO}$ toxicity, whereas $\mathrm{H}_{2}$ is removed by sulfate reduction, thus reducing end-product inhibition (Parshina et al. 2005). We investigated the cooccurrence of the potential thermophilic hydrogenogenic carboxydotrophs and other microbes using non-parametric Spearman correlations of phylotype presence/absence across all sampling sites. Among the phylotypes present in at least seven sites, networks between OTU_664 and four uncultured microbes, and between OTU_1000 and two uncultured bacteria were identified with a Spearman correlation coefficient $>0.8$ (Online Resource 9). There seem to be no specific symbiotic interactions between most of the potentially hydrogenogenic carboxydotrophic phylotypes and other microbes at these sampling sites.

A microbial population whose relative abundance is $<0.1 \%$ is called 'rare biosphere' and contributes to a persistent microbial seed bank, which is a collection of dormant microorganisms that can respond to favourable environmental conditions (Lynch and Neufeld 2015). Endospore formation has an important role for dormancy as well as microbial dispersal (Hubert et al. 2009; Müller et al. 2013; Zeigler 2014; Lynch and Neufeld 2015). It was considered that Firmicutes members of the potential thermophilic hydrogenogenic carboxydotrophs found in a variety of hot springs (in most case, as rare biosphere) might form endospores in extreme environmental conditions and have a strategy of microbial seed bank dynamics. The result that most of the potential hydrogenogenic carboxydotrophs did not show any symbiotic networks with other microbes also might support the speculation that metabolic activities of these members are low in extreme environments.

\section{Conclusion}

This study explored the distribution, diversity, and ecology of thermophilic carboxydotrophs across various hydrothermal environments using microbial community analysis. First, we searched CODH-ECH gene clusters in 
the current microbial genomic database and revealed 71 genomes encoding CODH-ECH gene clusters. Of these, 46 were genomes whose carriers have never been reported as hydrogenogenic carboxydotrophs. In a microbial community analysis, we identified 13 phylotypes that showed $>98.7 \%$ identity with thermophilic members of these taxa. Of these, 10 phylotypes were members of the phylum Firmicutes, and Parageobacillus, Carboxydocella, Caldanaerobacter, and Carboxydothermus phylotypes were found across geographically distant hot springs with different environmental conditions, wherein distinct microbial community structures were formed. Although the relative abundance of the Carboxydothermus and Carboxydocella phylotypes was greater than $1 \%$ at some sites, most of the potentially thermophilic hydrogenogenic carboxydotrophs were usually rare biospheres, whose relative abundances were $<0.1 \%$. They might be in dormant states in extreme environmental conditions. Although symbiotic interactions between hydrogenotrophic microbes and hydrogenogenic carboxydotrophs have been suggested (Parshina et al. 2005), no symbiotic interaction was identified between most of these phylotypes and other microbes in our study, leading to the speculation that thermophilic hydrogenogenic carboxydotrophic species might not be active in these environments. However, the previous sediment incubation and cultivation studies have shown that Carboxydothermus and Carboxydocella species respond to the presence of $\mathrm{CO}$ and actively grow (Kochetkova et al. 2011; Yoneda et al. 2012 , 2015; Brady et al. 2015). There is also evidence that an unusually high-density population (equivalent to $9.45 \times 10^{5}$ cells g sediment $^{-1}$ ) of Carboxydothermus is present in Unagi-onsen hot springs (Yoneda et al. 2013a), suggesting that they are viable in the environment. While further studies such as transcription analysis are needed to better understand the ecological function of thermophilic hydrogenogenic carboxydotrophs, the present study provides essential information concerning their distribution and diversity in a variety of volcanic environments.

Acknowledgements We are grateful to Eitaro Ikeda, Tatsuki Oguro, and Shin Fujiwara for their assistance during field sampling. We thank Masao Inoue and Issei Nakamoto for helping with computational analysis. Part of the computational analysis was completed at the Supercomputer System at the Institute for Chemical Research, Kyoto University.

Funding This study was supported by Grants-in-Aid for Scientific Research (A) 25252038, and (S) 16H06381 from The Ministry of Education, Culture, Sports, Science and Technology (MEXT) and by a Grant-in-Aid from the Japan Society for the Promotion of Science (JSPS) Fellows (16J11269).

\section{Compliance with ethical standards}

Conflict of interest None declared.
Open Access This article is distributed under the terms of the Creative Commons Attribution 4.0 International License (http://creativeco mmons.org/licenses/by/4.0/), which permits unrestricted use, distribution, and reproduction in any medium, provided you give appropriate credit to the original author(s) and the source, provide a link to the Creative Commons license, and indicate if changes were made.

\section{References}

Adam PS, Borrel G, Gribaldo S (2018) Evolutionary history of carbon monoxide dehydrogenase/acetyl-CoA synthase, one of the oldest enzymatic complexes. Proc Natl Acad Sci 115:E1166E1173. https://doi.org/10.1073/pnas.1716667115

Alex A, Antunes A (2015) Whole genome sequencing of the symbiont Pseudovibrio sp. from the intertidal marine sponge Polymastia penicillus revealed a gene repertoire for host-switching permissive lifestyle. Genome Biol Evol 7:3022-3032. https:// doi.org/10.1093/gbe/evv199

Alves JI, van Gelder AH, Alves MM et al (2013) Moorella stamsii sp. nov., a new anaerobic thermophilic hydrogenogenic carboxydotroph isolated from digester sludge. Int J Syst Evol Microbiol 63:4072-4076. https://doi.org/10.1099/ijs.0.050369-0

Bae SS, Kim YJ, Yang SH et al (2006) Thermococcus onnurineus sp. nov., a hyperthermophilic archaeon isolated from a deep-sea hydrothermal vent area at the PACMANUS field. J Microbiol Biotechnol 16:1826-1831

Barns SM, Fundyga RE, Jeffries MW, Pace NR (1994) Remarkable archaeal diversity detected in a Yellowstone National Park hot spring environment. Proc Natl Acad Sci USA 91:1609-1613. https://doi.org/10.1073/pnas.91.5.1609

Barns SM, Delwiche CF, Palmer JD, Pace NR (1996) Perspectives on archaeal diversity, thermophily and monophyly from environmental rRNA sequences. Proc Natl Acad Sci USA 93:91889193. https://doi.org/10.1073/pnas.93.17.9188

Bolger AM, Lohse M, Usadel B (2014) Trimmomatic: a flexible trimmer for Illumina sequence data. Bioinformatics 30:21142120. https://doi.org/10.1093/bioinformatics/btu170

Bott TL, Brock TD (1969) Bacterial growth rates above $90{ }^{\circ} \mathrm{C}$ in Yellowstone hot springs. Science 164:1411-1412. https://doi. org/10.1126/science.164.3886.1411

Brady A, Sharp C, Grasby S, Dunfield P (2015) Anaerobic carboxydotrophic bacteria in geothermal springs identified using stable isotope probing. Front Microbiol 6:897. https://doi.org/10.3389/ fmicb.2015.00897

Brock TD (1967) Life at high temperatures. Science 158:1012-1018. https://doi.org/10.1126/science.230.4722.132

Brock TD, Darland GK (1970) Limits of microbial existence: temperature and $\mathrm{pH}$. Science 169:1316-1318. https://doi. org/10.1126/science.169.3952.1316

Brock TD, Brock ML, Bott TL, Edwards MR (1971) Microbial life at $90{ }^{\circ} \mathrm{C}$ : the sulfur bacteria of Boulder Spring. J Bacteriol 107:303-314

Byrne-Bailey KG, Wrighton KC, Melnyk R et al (2010) Complete genome sequence of the electricity-producing "Thermincola potens" strain JR. J Bacteriol 192:4078-4079. https://doi. org/10.1128/JB.00044-10

Canganella F, Jones WJ, Gambacorta A, Antranikian G (1998) Thermococcus guaymasensis sp. nov. and Thermococcus aggregans sp. nov., two novel thermophilic archaea isolated from the Guaymas Basin hydrothermal vent site. Int J Syst Evol Microbiol 48:1181-1185. https://doi.org/10.1099/00207713-48-4-1181 
Esquivel-Elizondo S, Krajmalnik-Brown R, Maldonado J (2018) Anaerobic carbon monoxide metabolism by Pleomorphomonas carboxyditropha sp. nov., a new mesophilic hydrogenogenic carboxydotroph. FEMS Microbiol Ecol 94:fiy056. https://doi. org/10.1093/femsec/fiy056

Fardeau M-L, Salinas MB, L'Haridon S et al (2004) Isolation from oil reservoirs of novel thermophilic anaerobes phylogenetically related to Thermoanaerobacter subterraneus: reassignment of T. subterraneus, Thermoanaerobacter yonseiensis, Thermoanaerobacter tengcongensis and Carboxydibrachium pacificum to Caldanaerobacter subterraneus gen. nov., sp. nov., comb. nov. as four novel subspecies. Int J Syst Evol Microbiol 54:467-474. https://doi.org/10.1099/ijs.0.02711-0

Fukuyama Y, Oguro T, Omae K et al (2017) Draft genome sequences of two hydrogenogenic carboxydotrophic bacteria, Carboxydocella sp. strains JDF658 and ULO1, isolated from two distinct volcanic fronts in Japan. Genome Announc 5:e0242-17. https ://doi.org/10.1128/genomeA.00242-17

Fukuyama Y, Omae K, Yoneda Y et al (2018) Insight into energy conservation via alternative carbon monoxide metabolism in Carboxydothermus pertinax revealed by comparative genome analysis. Appl Environ Microbiol 84:e00458-18. https://doi. org/10.1128/AEM.00458-18

Haouari O, Fardeau M-L, Casalot L et al (2006) Isolation of sulfatereducing bacteria from Tunisian marine sediments and description of Desulfovibrio bizertensis sp. nov. Int J Syst Evol Microbiol 56:2909-2913. https://doi.org/10.1099/ijs.0.64530-0

Harada J, Yamada T, Giri S et al (2018) Draft genome sequence of Moorella sp. Strain Hama-1, a novel acetogenic bacterium isolated from a thermophilic digestion reactor. Microbiol Resour Announc 6:e00517. https://doi.org/10.1128/genomeA.00517-18

Hensley SA, Jung J-H, Park C-S, Holden JF (2014) Thermococcus paralvinellae sp. nov. and Thermococcus cleftensis $\mathrm{sp}$. nov. of hyperthermophilic heterotrophs from deep-sea hydrothermal vents. Int J Syst Evol Microbiol 64:3655-3659. https://doi. org/10.1099/ijs.0.066100-0

Hubert C, Loy A, Nickel M et al (2009) A constant flux of diverse thermophilic bacteria into the cold Arctic seabed. Science 325:1541-1544. https://doi.org/10.1126/science.1174012

Hugenholtz P, Pitulle C, Hershberger KL, Pace NR (1998) Novel division level bacterial diversity in a Yellowstone hot spring. J Bacteriol 180:366-376

Inoue M, Nakamoto I, Omae K et al (2019a) Structural and phylogenetic diversity of anaerobic carbon-monoxide dehydrogenases. Front Microbiol 9:3353. https://doi.org/10.3389/fmicb .2018 .03353

Inoue M, Tanimura A, Ogami Y et al (2019b) Draft genome sequence of strain TG4, a hydrogenogenic carboxydotrophic bacterium isolated from a marine sediment. Microbiol Resour Announc 8:e01666-18. https://doi.org/10.1128/MRA.01666-18

Itoh T, Suzuki K, Nakase T (2002) Vulcanisaeta distributa gen. nov., sp. nov., and Vulcanisaeta souniana sp. nov., novel hyperthermophilic, rod-shaped crenarchaeotes isolated from hot springs in Japan. Int J Syst Evol Microbiol 52:1097-1104. https://doi. org/10.1099/00207713-52-4-1097

Ji S, Zhao R, Li Z et al (2013) Ferrimonas sediminum sp. nov., isolated from coastal sediment of an amphioxus breeding zone. Int J Syst Evol Microbiol 63:977-981. https://doi.org/10.1099/ ijs.0.042408-0

Jiang B, Henstra A-M, Paulo PL et al (2009) Atypical one-carbon metabolism of an acetogenic and hydrogenogenic Moorella thermoacetica strain. Arch Microbiol 191:123-131. https://doi. org/10.1007/s00203-008-0435-x

Jung GY, Kim JR, Jung HO et al (1999) A new chemoheterotrophic bacterium catalyzing water-gas shift reaction. Biotechnol Lett 21:869-873. https://doi.org/10.1023/A:1005599600510
Katoh K, Standley DM (2013) MAFFT multiple sequence alignment software version 7: improvements in performance and usability. Mol Biol Evol 30:772-780. https://doi.org/10.1093/molbev/mst01 0

Kerby RL, Hong SS, Ensign S et al (1992) Genetic and physiological characterization of the Rhodospirillum rubrum carbon monoxide dehydrogenase system. J Bacteriol 174:5284-5294. https://doi. org/10.1128/jb.174.16.5284-5294.1992

Khelaifia S, Fardeau M-L, Pradel N et al (2011) Desulfovibrio piezophilus sp. nov., a piezophilic, sulfate-reducing bacterium isolated from wood falls in the Mediterranean Sea. Int J Syst Evol Microbiol 61:2706-2711. https://doi.org/10.1099/ijs.0.028670-0

Kim BC, Grote R, Lee DW et al (2001) Thermoanaerobacter yonseiensis sp. nov., a novel extremely thermophilic, xylose-utilizing bacterium that grows at up to $85^{\circ} \mathrm{C}$. Int J Syst Evol Microbiol 51:1539-1548. https://doi.org/10.1099/00207713-51-4-1539

Kochetkova TV, Rusanov II, Pimenov NV et al (2011) Anaerobic transformation of carbon monoxide by microbial communities of Kamchatka hot springs. Extremophiles 15:319-325. https://doi. org/10.1007/s00792-011-0362-7

Kozhevnikova DA, Taranov EA, Lebedinsky AV et al (2016) Hydrogenogenic and sulfidogenic growth of Thermococcus archaea on carbon monoxide and formate. Microbiology 85:400-410. https ://doi.org/10.1134/S0026261716040135

Letunic I, Bork P (2016) Interactive tree of life (iTOL) v3: an online tool for the display and annotation of phylogenetic and other trees. Nucleic Acids Res 44:W242-W245. https://doi.org/10.1093/nar/ gkw290

Lynch MDJ, Neufeld JD (2015) Ecology and exploration of the rare biosphere. Nat Rev Microbiol 13:217-229. https://doi. org/10.1038/nrmicro3400

Marchler-Bauer A, Panchenko AR, Shoemaker B et al (2002) CDD: a database of conserved domain alignments with links to domain three-dimensional structure. Nucleic Acids Res 30:281-283. https ://doi.org/10.1093/nar/30.1.281

Marteinsson VT, Birrien JL, Reysenbach AL et al (1999) Thermococcus barophilus sp. nov., a new barophilic and hyperthermophilic archaeon isolated under high hydrostatic pressure from a deep-sea hydrothermal vent. Int J Syst Bacteriol 49:351-359. https://doi. org/10.1099/00207713-49-2-351

McMurdie PJ, Holmes S (2013) phyloseq: An R package for reproducible interactive analysis and graphics of microbiome census data. PLoS One 8:e61217. https://doi.org/10.1371/journal.pone.00612 17

Mohr T, Aliyu H, Küchlin R et al (2018) CO-dependent hydrogen production by the facultative anaerobe Parageobacillus thermoglucosidasius. Microb Cell Fact 17:108. https://doi.org/10.1186/ s12934-018-0954-3

Mori K, Hanada S, Maruyama A, Marumo K (2002) Thermanaeromonas toyohensis gen. nov., sp. nov., a novel thermophilic anaerobe isolated from a subterranean vein in the Toyoha Mines. Int J Syst Evol Microbiol 52:1675-1680. https://doi.org/10.1099/00207 713-52-5-1675

Müller AL, de Rezende JR, Hubert CRJ et al (2013) Endospores of thermophilic bacteria as tracers of microbial dispersal by ocean currents. ISME J 8:1153-1165. https://doi.org/10.1038/ ismej.2013.225

Munk AC, Copeland A, Lucas S et al (2011) Complete genome sequence of Rhodospirillum rubrum type strain $\left(\mathrm{S}^{\mathrm{T}}{ }^{\mathrm{T}}\right)$. Stand Genomic Sci 4:293-302. https://doi.org/10.4056/sigs.1804360

Nakagawa T, Iino T, Suzuki K, Harayama S (2006) Ferrimonas futtsuensis sp. nov. and Ferrimonas kyonanensis sp. nov., selenatereducing bacteria belonging to the Gammaproteobacteria isolated from Tokyo Bay. Int J Syst Evol Microbiol 56:2639-2645. https://doi.org/10.1099/ijs.0.64399-0 
Nevin KP, Holmes DE, Woodard TL et al (2005) Geobacter bemidjiensis sp. nov. and Geobacter psychrophilus sp. nov., two novel $\mathrm{Fe}(\mathrm{III})$-reducing subsurface isolates. Int J Syst Evol Microbiol 55:1667-1674. https://doi.org/10.1099/ijs.0.63417-0

Novikov AA, Sokolova TG, Lebedinsky AV et al (2011) Carboxydothermus islandicus sp. nov., a thermophilic, hydrogenogenic, carboxydotrophic bacterium isolated from a hot spring. Int J Syst Evol Microbiol 61:2532-2537. https://doi.org/10.1099/ ijs.0.030288-0

Oda Y, Larimer FW, Chain PSG et al (2008) Multiple genome sequences reveal adaptations of a phototrophic bacterium to sediment microenvironments. Proc Natl Acad Sci 105:1854318548. https://doi.org/10.1073/pnas.0809160105

Oh Y-K, Kim H-J, Park S et al (2008) Metabolic-flux analysis of hydrogen production pathway in Citrobacter amalonaticus Y19. Int J Hydrogen Energy 33:1471-1482. https://doi.org/10.1016/j. ijhydene.2007.09.032

Oksanen J, Blanchet FG, Friendly M et al (2017) Vegan: community ecology package. R package version 2.4-3. https://CRAN.Rproject.org/package $=$ vegan

Oshima T, Imahori K (1974) Description of Thermus thermophilus (Yoshida and Oshima) comb. nov., a nonsporulating thermophilic bacterium from a Japanese thermal spa. Int J Syst Bacteriol 24:102-112. https://doi.org/10.1099/00207713-24-1-102

Parshina SN, Kijlstra S, Henstra AM et al (2005) Carbon monoxide conversion by thermophilic sulfate-reducing bacteria in pure culture and in co-culture with Carboxydothermus hydrogenoformans. Appl Microbiol Biotechnol 68:390-396. https://doi. org/10.1007/s00253-004-1878-x

Peng T, Pan S, Christopher LP et al (2016) Growth and metabolic profiling of the novel thermophilic bacterium Thermoanaerobacter sp. strain YS13. Can J Microbiol 62:762-771. https://doi. org/10.1139/cjm-2016-0040

Pierce E, Xie G, Barabote RD et al (2008) The complete genome sequence of Moorella thermoacetica (f. Clostridium thermoaceticum). Environ Microbiol 10:2550-2573. https://doi.org/10.11 11/j.1462-2920.2008.01679.x

Price MN, Dehal PS, Arkin AP (2010) FastTree 2-approximately maximum-likelihood trees for large alignments. PLoS One 5:e9490. https://doi.org/10.1371/journal.pone.0009490

Pruesse E, Peplies J, Glöckner FO (2012) SINA: Accurate highthroughput multiple sequence alignment of ribosomal RNA genes. Bioinformatics 28:1823-1829. https://doi.org/10.1093/ bioinformatics/bts 252

Quast C, Pruesse E, Yilmaz P et al (2013) The SILVA ribosomal RNA gene database project: Improved data processing and web-based tools. Nucleic Acids Res 41:590-596. https://doi. org/10.1093/nar/gks1219

R Core Team (2016) R: a language and environment for statistical computing. R Foundation for Statistical Computing, Vienna. https://www.R-project.org

Reysenbach A, Wickham GS, Pace NR (1994) Phylogenetic analysis of the hyperthermophilic pink filament community in Octopus Spring, Yellowstone National Park. Appl Environ Microbiol 60:2113-2119

Rognes T, Flouri T, Nichols B et al (2016) VSEARCH: a versatile open source tool for metagenomics. PeerJ 4:e2584. https://doi. org/10.7717/peerj.2584

Sant'Anna F, Lebedinsky A, Sokolova T et al (2015) Analysis of three genomes within the thermophilic bacterial species Caldanaerobacter subterraneus with a focus on carbon monoxide dehydrogenase evolution and hydrolase diversity. BMC Genom 16:757. https://doi.org/10.1186/s12864-015-1955-9

Schuchmann K, Müller V (2014) Autotrophy at the thermodynamic limit of life: a model for energy conservation in acetogenic bacteria. Nat Rev Microbiol 12:809-821. https://doi.org/10.1038/ nrmicro3365

Sharp CE, Brady AL, Sharp GH et al (2014) Humboldt's spa: microbial diversity is controlled by temperature in geothermal environments. ISME J 8:1166-1174. https://doi.org/10.1038/ismej.2013.237

Shelobolina ES, Nevin KP, Blakeney-Hayward JD et al (2007) Geobacter pickeringii sp. nov., Geobacter argillaceus sp. nov. and Pelosinus fermentans gen. nov., sp. nov., isolated from subsurface kaolin lenses. Int J Syst Evol Microbiol 57:126-135. https://doi. org/10.1099/ijs.0.64221-0

Singer SW, Hirst MB, Ludden PW (2006) CO-dependent $\mathrm{H}_{2}$ evolution by Rhodospirillum rubrum: Role of CODH:CooF complex. Biochim Biophys Acta Bioenerg 1757:1582-1591. https://doi. org/10.1016/j.bbabio.2006.10.003

Slepova TV, Sokolova TG, Lysenko AM et al (2006) Carboxydocella sporoproducens $\mathrm{sp}$. nov., a novel anaerobic $\mathrm{CO}$-utilizing/ $\mathrm{H}_{2}$-producing thermophilic bacterium from a Kamchatka hot spring. Int J Syst Evol Microbiol 56:797-800. https://doi.org/10.1099/ ijs.0.63961-0

Slobodkin A, Reysenbach AL, Mayer F, Wiegel J (1997) Isolation and characterization of the homoacetogenic thermophilic bacterium Moorella glycerini sp. nov. Int J Syst Bacteriol 47:969-974. https ://doi.org/10.1099/00207713-47-4-969

Slobodkin AI, Sokolova TG, Lysenko AM, Wiegel J (2006) Reclassification of Thermoterrabacterium ferrireducens as Carboxydothermus ferrireducens comb. nov., and emended description of the genus Carboxydothermus. Int J Syst Evol Microbiol 56:2349 2351. https://doi.org/10.1099/ijs.0.64503-0

Sokolova TG, González JM, Kostrikina NA et al (2001) Carboxydobrachium pacificum gen. nov., sp. nov., a new anaerobic, thermophilic, CO-utilizing marine bacterium from Okinawa Trough. Int J Syst Evol Microbiol 51:141-149. https://doi.org/10.1099/00207 713-51-1-141

Sokolova TG, Kostrikina NA, Chernyh NA et al (2002) Carboxydocella thermautotrophica gen. nov., sp. nov., a novel anaerobic, CO-utilizing thermophile from a Kamchatkan hot spring. Int J Syst Evol Microbiol 52:1961-1967. https://doi.org/10.1099/00207 713-52-6-1961

Sokolova TG, González JM, Kostrikina NA et al (2004a) Thermosinus carboxydivorans gen. nov., sp. nov., a new anaerobic, thermophilic, carbon-monoxide-oxidizing, hydrogenogenic bacterium from a hot pool of Yellowstone National Park. Int J Syst Evol Microbiol 54:2353-2359. https://doi.org/10.1099/ijs.0.63186-0

Sokolova TG, Jeanthon C, Kostrikina NA et al (2004b) The first evidence of anaerobic $\mathrm{CO}$ oxidation coupled with $\mathrm{H}_{2}$ production by a hyperthermophilic archaeon isolated from a deep-sea hydrothermal vent. Extremophiles 8:317-323. https://doi.org/10.1007/ s00792-004-0389-0

Sokolova TG, Henstra A-M, Sipma J et al (2009) Diversity and ecophysiological features of thermophilic carboxydotrophic anaerobes. FEMS Microbiol Ecol 68:131-141. https://doi.org/10.111 1/j.1574-6941.2009.00663.x

Srinivas TNR, Bhaskar YV, Bhumika V, Kumar PA (2013) Photobacterium marinum sp. nov., a marine bacterium isolated from a sediment sample from Palk Bay India. Syst Appl Microbiol 36:160-165. https://doi.org/10.1016/j.syapm.2012.12.002

Suzuki Y, Kishigami T, Inoue K et al (1983) Bacillus thermoglucosidasius sp. nov., a new species of obligately Thermophilic Bacilli. Syst Appl Microbiol 4:487-495. https://doi.org/10.1016/S0723 -2020(83)80006-X

Svetlichny VA, Sokolova TG, Gerhardt M et al (1991) Carboxydothermus hydrogenoformans gen. nov., sp. nov., a CO-utilizing thermophilic anaerobic bacterium from hydrothermal environments of Kunashir Island. Syst Appl Microbiol 14:254-260. https://doi. org/10.1016/S0723-2020(11)80377-2 
Takahashi S, Tomita J, Nishioka K et al (2014) Development of a prokaryotic universal primer for simultaneous analysis of bacteria and archaea using next-generation sequencing. PLoS One 9:e105592. https://doi.org/10.1371/journal.pone.0105592

Tatusov RL (2001) The COG database: new developments in phylogenetic classification of proteins from complete genomes. Nucleic Acids Res 29:22-28. https://doi.org/10.1093/nar/29.1.22

Techtmann SM, Colman AS, Robb FT (2009) "That which does not kill us only makes us stronger": the role of carbon monoxide in thermophilic microbial consortia. Environ Microbiol 11:1027-1037. https://doi.org/10.1111/j.1462-2920.2009.01865.x

Techtmann SM, Lebedinsky AV, Colman AS et al (2012) Evidence for horizontal gene transfer of anaerobic carbon monoxide dehydrogenases. Front Microbiol 3:1-16. https://doi.org/10.3389/fmicb .2012 .00132

Toshchakov SV, Lebedinsky AV, Sokolova TG et al (2018) Genomic insights into energy metabolism of Carboxydocella thermautotrophica coupling hydrogenogenic $\mathrm{CO}$ oxidation with the reduction of Fe(III) minerals. Front Microbiol 9:1759. https://doi. org/10.3389/fmicb.2018.01759

Wrighton KC, Agbo P, Warnecke F et al (2008) A novel ecological role of the Firmicutes identified in thermophilic microbial fuel cells. ISME J 2:1146-1156. https://doi.org/10.1038/ismej.2008.48

Wu M, Ren Q, Durkin S et al (2005) Life in hot carbon monoxide: the complete genome sequence of Carboxydothermus hydrogenoformans Z-2901. PLoS Genet 1:e65. https://doi.org/10.1371/journ al.pgen.0010065

Yoneda Y, Yoshida T, Kawaichi S et al (2012) Carboxydothermus pertinax sp. nov., a thermophilic, hydrogenogenic, $\mathrm{Fe}(\mathrm{III})$-reducing, sulfur-reducing carboxydotrophic bacterium from an acidic hot spring. Int J Syst Evol Microbiol 62:1692-1697. https://doi. org/10.1099/ijs.0.031583-0

Yoneda Y, Yoshida T, Daifuku T et al (2013) Quantitative detection of carboxydotrophic bacteria Carboxydothermus in a hot aquatic environment. Fundam Appl Limnol 182:161-170. https://doi. org/10.1127/1863-9135/2013/0374

Yoneda Y, Yoshida T, Yasuda H et al (2013) A thermophilic, hydrogenogenic and carboxydotrophic bacterium, Calderihabitans maritimus gen. nov., sp. nov., from a marine sediment core of an undersea caldera. Int J Syst Evol Microbiol 63:3602-3608. https ://doi.org/10.1099/ijs.0.050468-0

Yoneda Y, Kano SI, Yoshida T et al (2015) Detection of anaerobic carbon monoxide-oxidizing thermophiles in hydrothermal environments. FEMS Microbiol Ecol 91:fiv093. https://doi.org/10.1093/ femsec/fiv093

Zavarzina DG, Sokolova TG, Tourova TP et al (2007) Thermincola ferriacetica sp. nov., a new anaerobic, thermophilic, facultatively chemolithoautotrophic bacterium capable of dissimilatory Fe(III) reduction. Extremophiles 11:1-7. https://doi.org/10.1007/s0079 2-006-0004-7

Zeigler DR (2014) The Geobacillus paradox: why is a thermophilic bacterial genus so prevalent on a mesophilic planet? Microbiology 160:1-11. https://doi.org/10.1099/mic.0.071696-0

Publisher's Note Springer Nature remains neutral with regard to jurisdictional claims in published maps and institutional affiliations. 